\title{
Are Commercial Complementary Food Distributions to Refugees and Migrants in Europe Conforming to International Policies and Guidelines on Infant and Young Child Feeding in Emergencies?
}

\author{
Melissa Ann Theurich, BSc, MPH' and \\ Veit Grote, MD, MSc'
}

\begin{abstract}
In 2015, more than one million migrants and refugees arrived in Europe. Commercial complementary foods, processed foods marketed for infants and young children 6-23 months of age, were distributed by various humanitarian actors along migrant routes and in European refugee camps. Unsolicited donations and distributions of commercial complementary food products were problematic and divergent from international policies on infant and young child feeding during humanitarian emergencies. Interim guidance regarding commercial complementary foods was published during the peak of the emergency but implemented differently by various humanitarian actors. Clearer and more technical specifications on commercial complementary foods are needed in order to objectively determine their suitability for operational contexts in Europe and emergency nutrition assistance in the future.
\end{abstract}

\section{Keywords}

breastfeeding, complementary feeding, disasters, exclusive breastfeeding, International Code of Marketing of Breast-milk Substitutes

\section{Background}

In 2015, more than one million migrants and refugees, mostly from Syria, Afghanistan, and Iraq, arrived in Europe (Eurostat Newsrelease, 2016). In January 2016, 55\% of refugees and migrants were women, infants, or children, whereas 1 in every 10 women was pregnant (Clayton, 2016; Ramrayka, 2016). Leading up to the large migration of people to Europe, national assessments in Syria, Afghanistan, and Iraq showed $42 \%, 58 \%$, and $20 \%$ exclusive breastfeeding rates in infants younger than 6 months, respectively (Mboya, 2014; United Nations Children's Fund [UNICEF], 2013; World Health Organization [WHO], 2014).

Breastfeeding is promoted worldwide for the prevention of infant deaths and illness during natural disasters, infectious disease outbreaks, armed conflicts, large-scale migrations, and refugee settings (Aakre et al., 2016; Biks, Berhane, Worku, \& Gete, 2015; United Nations News Centre, 2013). Women who give birth before or during long migrations are at higher risk of never initiating or cessation of breastfeeding (International Office of Migration \& UNICEF, 2015). In 2015 , breastfeeding practices among migrants in Europe were prevalent but suboptimal due to inadequate privacy, long transit times, and low contact and follow-up with skilled Infant and Young Child Feeding (IYCF) workers (UNICEF, United Nations High Commissioner for Refugees [UNHCR], Save the Children, \& Emergency Nutrition Network, 2015).

During emergencies, there is widespread misconception among mothers, humanitarian workers, the media, and the public that inadequate nutrition and stress impede production of milk (Gribble, 2013; WHO, 2016). This fallacy contributes to philanthropic efforts to distribute infant formula and commercial complementary food (CCF). Yet, blanket distributions of infant formula and CCF during emergencies have catastrophic effects on breastfeeding rates and infant health

\footnotetext{
'Department for Metabolic and Nutritional Medicine, Dr. von Hauner Children's Hospital, Ludwig-Maximilians-University of Munich, Munich, Bavaria, Germany

Date submitted: November 16, 2016; Date accepted: April II, 2017

Corresponding Author:

Melissa Ann Theurich, BSc, MPH, Department for Metabolic and

Nutritional Medicine, Dr. von Hauner Children's Hospital, Ludwig-

Maximilians-University of Munich, Munich, Bavaria, Germany.

Email: melissa@theurichconsulting.com
} 
(Carothers \& Gribble, 2014; Hipgrave, Assefa, Winoto, \& Sukotjo, 2011; WHO, 2016).

Commercial complementary foods are processed foods marketed for infants and young children 6-23 months of age. Ready-to-use CCF includes pureed fruits or vegetables, meals containing combinations of vegetables and meat, ready-to-eat pasta or other grain dishes, desserts, and infant biscuits, whereas other CCF requires reconstitution with liquids, including powdered infant cereals and dehydrated or freeze-dried meat products.

At the beginning of 2016, a nonprofit organization donated 22 metric tons of infant formula and CCF to refugees in Greek border camps (Human Plus e.V., 2016), whereas another organization delivered 10,000 jars of commercial infant desserts from Germany (Matz \& Kessler, 2016). Upon arrival to Austria, migrants were greeted with "welcome kits," compiled with assistance from the public and the federal postal service, which accepted mailed donations and waived postage fees for 12,000 gift boxes containing infant formula and CCF (Samariter Bund, 2015; Sozialdemokratische Partei Österreichs, 2015). In a separate effort, CCF was distributed by the Austrian military to refugee families en route to Germany (Gallup, 2015).

\section{Suitability of CCF for Feeding Infants and Young Children Seeking Refuge in Europe}

Well-meaning donations of infant formula are rarely suitable in emergencies because they are often expired and labeled in the wrong language or the wrong nutrition composition (Carothers \& Gribble, 2014). The same shortfalls hold true for donations of CCF in emergencies, including those distributed in Europe during 2015 and 2016 (Modigell, Fernandes, \& Gayford, 2016; Theurich, 2016). For example, in camps along the border of Croatia and Serbia, a baby food company pushed to donate five metric tons of nearly expired CCF (Modigell et al., 2016). Donated CCF had low nutrition quality, with the majority of products being unfortified fruit and vegetable purees or infant desserts (UNICEF et al., 2015). Commercial complementary food was not in the end user language, and humanitarian workers could not read CCF labels printed in foreign languages (Theurich, 2016). One organization reported investigating the cost of translating food labels into Arabic, Farsi, and English, but this proved to be too expensive and cumbersome (Modigell et al., 2016).

Exclusive breastfeeding until 6 months of age is crucial during emergencies because it is protective against pneumonia and diarrheal diseases (Lamberti, Fischer Walker, Noiman, Victora, \& Black, 2011; Lamberti et al., 2013), two of the most common causes of death in children living in refugee camps (Hershey et al., 2011). Yet, some CCF labels promoted introduction of complementary foods starting from 4 months of age (Modigell et al., 2016; Theurich, 2016).

\section{Key messages}

- Unsolicited donations and distributions of commercial complementary foods are problematic along migrant routes and in European refugee camps

- European food labels recommend commercial complementary foods from four months of age, contradicting the Operational Guidance on Infant and Young Child Feeding in Emergencies (IYCF-E) and international policies recommending exclusive breastfeeding for six months

- Interim operational guidance published during the crisis regarding commercial complementary foods were interpreted and implemented differently by various humanitarian actors

- Clearer technical guidance on nutritional appropriateness, food safety, storage and hygienic handling is needed in order to determine suitability of commercial complementary foods in emergency operational contexts in Europe

In the context of a mainly Islamic refugee population, European CCF may not be culturally appropriate and may undermine traditional complementary feeding practices. According to field reports, some migrant mothers had refused unfamiliar CCF if not labeled as halal (Modigell et al., 2016; Theurich, 2016). This is because CCF from Europe may contain pork and other meat that does not adhere to the Muslim refugee population's religious dietary restrictions.

In nonemergency contexts, there is evidence that marketing of CCF indirectly encourages use of infant formula (Smith et al., 2015). Some marketing also directly or indirectly encourages premature introduction of foods and displacement of suitable traditional complementary foods (Smith et al., 2015). Although there is limited research on the effect of promotion of CCF in emergencies, one study examined CCF distributions following the 2006 earthquake in Indonesia (Hipgrave et al., 2011). The study showed that households with young infants (0-5 months of age) that had received commercial porridges or blended fortified foods used these products more readily than households that had not received donations, despite the infants being too young to consume complementary foods (Hipgrave et al., 2011).

\section{Current Guiding Documents on CCF in Emergencies}

In European refugee camps, CCF distribution varies by organization and location. This is due in part to gaps in national and international policies on use of CCF in emergencies. Globally, the foremost international policy to protect, promote, and support breastfeeding is the International 
Code of Marketing of Breast-milk Substitutes (The Code) and subsequent World Health Assembly (WHA) resolutions (WHO, 2017). The Code defines a breast-milk substitute as any food being marketed or otherwise presented as a partial or total replacement for breast milk (WHO, 2017). Most European countries have enacted legislation or other legal measures of The Code. However, under the scope of their national legislations, provisions in many European countries exclude regulation on marketing of complementary foods (WHO, UNICEF, \& International Baby Food Action Network, 2016). WHA resolution 54.2 updated the recommendations on exclusive breastfeeding to 6 months, instead of 4 to 6 months (WHO, 2017). WHA 49.15 urges that complementary foods are not marketed in ways that undermine exclusive and sustained breastfeeding, and WHA 63.23 states that national and international preparedness plans and emergency responses should follow the Operational Guidance on Infant and Young Child Feeding in Emergencies (IYCF-E) (WHO, 2017).

The Operational Guidance gives practical directions on providing nutritionally adequate and safe complementary foods from 6 months of life with continued breastfeeding for up to 2 years of age or beyond and discourages provision of complementary food to infants younger than 6 months (WHO, 2017; WHO et al., 2007). It underlines that bottle-fed complementary foods or any foods and beverages marketed for infants younger than 6 months are considered breast-milk substitutes and discourages solicitation, acceptance of donations, and using expensive $\mathrm{CCF}$ or undermining traditional complementary feeding practices (WHO, 2017; WHO et al., 2007). Local CCF labeling directives that authorize solid food introduction from 4 months of age deviate from the global recommendations and, in emergency contexts, are not in line with international guidelines for IYCF-E (WHO, 2017; WHO et al., 2007).

The Sphere Project, which publishes minimum standards for IYCF in humanitarian response, states to uphold The Code and the Operational Guidance on IYCF-E and advises to avoid solicitation of breast-milk substitutes and other milk products, bottles, and teats but does not mention avoiding donations of CCF specifically (The Sphere Project, 2011).

\section{Nutrition Considerations}

There are no established minimum nutrition specifications for $\mathrm{CCF}$ in emergencies. Current guidance gives practical but limited technical nutrition advice on CCF (WHO et al., 2007). The Sphere Project also does not offer minimum standards for nutrition adequacy of CCF (The Sphere Project, 2011).

Due to the lack of contextual guidance on CCF and other nutrition issues, in 2015 interim operational considerations on
IYCF-E for refugee and migratory settings in Europe were published (UNICEF et al., 2015). This document stated that CCF may be used as a "practical stop gap" where appropriate and acceptable during this particular emergency response. However, in practice, the stop gap was interpreted differently by different actors in different places. Implementation ranged from distribution of CCF alone, to CCF as part of a supplementary food package together with ready-to-use supplementary food (Modigell et al., 2016), to CCF with fresh fruit only (Theurich, 2016), to CCF with ultra-high-temperatureprocessed milk and high-energy biscuits (Danish Refugee Council, 2016). Some humanitarian workers were not aware that unfortified CCF fruit and vegetable purees are nutritionally inferior to fortified complementary foods or breast milk (Theurich, 2016).

With a view to the double burden of malnutrition, provision of sugary CCF like infant biscuits and desserts in refugee camps is concerning. Commercial complementary food with excessive sugar or calories, excessive portion sizes, or marketing of early or frequent feedings displaces rather than complements breast milk and may therefore undermine continued breastfeeding (Smith et al., 2015). Hence, clearer technical guidance is needed to objectively determine nutrition adequacy of CCF in operational contexts.

\section{Recommendations}

Implementation of IYCF policies regarding donating, soliciting, accepting, or promoting infant formula and CCF should be upheld in the context of the current influx of refugees and migrants in Europe. Blanket distributions of CCF in emergencies have been shown to increase the incidence of premature introduction of solid foods (Hipgrave et al., 2011). Although the effect in emergencies has not yet been studied, in nonemergencies, marketing of CCF may undermine sustained breastfeeding in older infants (Smith et al., 2015). For these reasons, distribution of CCF without appropriate labeling in the end user language or adequate IYCF-E counseling is not in line with international guidelines.

European governments should collaborate to cease solicitation of donations and blanket distributions of infant formula and CCF in camps and along migrant routes. Measures to protect and promote breastfeeding should be undertaken and consistent messaging on timely, safe, and appropriate complementary feeding should be provided to all parents.

Globally, the WHO recommends introduction of complementary foods from 6 months of age and guidance documents uphold this recommendation in emergencies (UNICEF et al., 2015; WHO et al., 2007). Since emergencies can strike anywhere and at any time, as a means of disaster preparedness, local CCF labeling directives should consider recent experiences from European emergencies and adapt $\mathrm{CCF}$ labeling requirements. 


\section{Conclusion}

Donations of infant formula and CCF continued to be problematic in European refugee camps in 2016. These experiences highlight current policy gaps and the need for comprehensive international guidelines for the use of $\mathrm{CCF}$ in emergencies. Clear specifications on the acceptability, nutritional appropriateness, cost, labeling requirements, and information on food safety, storage, and hygienic handling of CCF are needed.

\section{Declaration of Conflicting Interests}

The authors declared no potential conflicts of interest with respect to the research, authorship, and/or publication of this article.

\section{Funding}

The authors received no financial support for the research, authorship, and/or publication of this article.

\section{References}

Aakre, I., Lilleengen, A. M., Lerseth Aarsand, M., Strand, T. A., Barikmo, I., \& Henjum, S. (2016). Infant feeding practices in the Saharawi refugee camps Algeria, a cross-sectional study among children from birth to six months of age. International Breastfeeding Journal, 12(8). doi:10.1186/s13006-016-0098-1

Biks, G. A., Berhane, Y., Worku, A., \& Gete, Y. K. (2015). Exclusive breast feeding is the strongest predictor of infant survival in Northwest Ethiopia: A longitudinal study. Journal of Health, Population, and Nutrition, 34, 9.

Carothers, C., \& Gribble, K. (2014). Infant and young child feeding in emergencies. Journal of Human Lactation, 30(3), 272-275.

Clayton, J. (2016). Refugee women on the move in Europe are at risk, says UN. Retrieved from http://www.unhcr.org/en-us/ news/latest/2016/1/569fb22b6/refugee-women-move-europerisk-says-un.html

Danish Refugee Council. (2016). Opening of child friendly space and mother and baby corner in Bujanovac. Retrieved from https://www.drc.org.rs/news/opening-of-child-friendly-spaceand-mother-and-baby-corner-in-bujanovac

Eurostat Newsrelease. (2016). Record number of over 1.2 million first time asylum seekers registered in 2015. Retrieved from http://ec.europa.eu/eurostat/documents/2995521/7203832/304032016-AP-EN.pdf/790eba01-381c-4163-bcd2-a54959b99ed6

Gallup, S. (2015). Germany reinstates border controls to stem migrant influx. Retrieved from http://www.zimbio.com/pictures/QAJYxtjBsvc/Germany+Reinstates+Border+Controls $+\mathrm{S}$ tem+Migrant/dmBPJJ3n49k

Gribble, K. D. (2013). Media messages and the needs of infants and young children after Cyclone Nargis and the WenChuan earthquake. Disasters, 37(1), 80-100. doi:10.1111/j.14677717.2012.01289.x

Hershey, C. L., Doocy, S., Anderson, J., Haskew, C., Spiegel, P., $\&$ Moss, W. J. (2011). Incidence and risk factors for malaria, pneumonia and diarrhea in children under 5 in UNHCR refugee camps: A retrospective study. Conflict and Health, 5(1), 24. doi:10.1186/1752-1505-5-24

Hipgrave, D., Assefa, F., Winoto, A., \& Sukotjo, S. (2011). Donated breast milk substitutes and incidence of diarrhoea among infants and young children after the May 2006 earthquake in Yogyakarta and Central Java. Public Health Nutrition, 15(2), 307-315.

Human Plus e.V. (2016). Support for refugees at the GreekMacedonian border. Retrieved from https://www.facebook. com/249381571748646/photos/a.885190574834406.1073741 $826.249381571748646 / 1129583833728411 /$ ?type $=3 \&$ theater

International Office of Migration \& UNICEF. (2015). Data brief: Migration of children to Europe. Retrieved from http://www. iom.int/sites/default/files/press_release/file/IOM-UNICEF-DataBrief-Refugee-and-Migrant-Crisis-in-Europe-30.11.15.pdf

Lamberti, L. M., Fischer Walker, C. L., Noiman, A., Victora, C., \& Black, R. E. (2011). Breastfeeding and the risk for diarrhea morbidity and mortality. BioMed Central Public Health, 11(Suppl. 3), S15. doi:10.1186/1471-2458-11-s3-s15

Lamberti, L. M., Zakarija-Grkovic, I., Fischer Walker, C. L., Theodoratou, E., Nair, H., Campbell, H., \& Black, R. E. (2013). Breastfeeding for reducing the risk of pneumonia morbidity and mortality in children under two: A systematic literature review and meta-analysis. BioMed Central Public Health, 13(Suppl. 3), S18. doi:10.1186/1471-2458-13-S3-S18

Matz, N., \& Kessler, F. (2016). Holidays in misery. Jetzt. Retrieved from http://www.jetzt.de/fluechtlinge/bericht-von-helfern-ausidomeni

Mboya, S. (2014). Artificial feeding in emergencies: Experiences from the ongoing Syrian crisis. Retrieved from the Field Exchange Emergency Nutrition Network website: http://www. ennonline.net/fex/48/artificialfeeding

Modigell, I., Fernandes, C., \& Gayford, M. (2016). Save the Children's IYCF-E rapid response in Croatia. Retrieved from the Field Exchange Emergency Nutrition Network website: http://www.ennonline.net/fex/52/rapidresponseincroatia

Ramrayka, L. (2016). The quiet crisis of Europe's pregnant refugees. Retrieved from http://www.huffingtonpost.com/entry/ europe-pregnant-refugees_us_575eba7ce4b0ced23ca88e5e

Samariter Bund. (2015). Donations. Retrieved from http://www. samariterbund.net/aktion-menschlichkeit/sachspenden/

Smith, J. P., Sargent, G. M., Mehta, K., James, J., Berry, N., Koh, C., . . Blake, M. (2015). A rapid evidence assessment: Does marketing of commercially available complementary foods affect infant and young child feeding? Report to the World Health Organization. Retrieved from http://www.who.int/entity/nutrition/topics/CF_anu_effects_marketingcommercial.pdf?ua $=1$

Sozialdemokratische Partei Österreichs. (2015). Welcome packages for refugees. Retrieved from https://frauen.spoe.at/story/ samariterbund-und-post-starten-am-9-september-aktionwillkommenspakete-fuer-fluechtlinge

The Sphere Project. (2011). Humanitarian Charter and Minimum Standards in Humanitarian Response. Retrieved from http:// spherehandbook.org/

Theurich, M. (2016). [IYCF-E field report: Refugee camp in Polycastro, Greece]. Unpublished field report.

United Nations Children's Fund. (2013). Statistics. Retrieved from http://www.unicef.org/infobycountry/iraq_statistics.html

United Nations Children's Fund, United Nations High Commissioner for Refugees, Save the Children, \& Emergency Nutrition Network. (2015). Interim operational considerations for the feeding support of infants and young children under 2 years of age in refugee and migrant transit settings in Europe. Retrieved from $\mathrm{http}: / /$ www.ennonline.net/interimconsiderationsiycftransit 
United Nations News Centre. (2013). United Nations agencies promote breastfeeding to protect babies in typhoon-hit Philippines. Retrieved from http://www.un.org/apps/news/ story.asp?NewsID $=46625$ \#.WOeZ8aIIFPY

World Health Organization. (2014). A winning goal for life: World Breastfeeding Week celebrated in Afghanistan. Retrieved from http://www.emro.who.int/afg/afghanistan-events/worldbreastfeeding-week-afghanistan-2014.html

World Health Organization. (2016). Migration and health: Key issues. Retrieved from http://www.euro.who.int/en/health-topics/healthdeterminants/migration-and-health/migrant-health-in-the-european-region/migration-and-health-key-issues\#292115

World Health Organization. (2017). The international code of marketing of breast-milk substitutes-2017 update: Frequently asked questions. Retrieved from http://www.who. int/nutrition/publications/infantfeeding/breastmilk-substitutes-FAQ2017/en/

World Health Organization, United Nations Children's Fund, \& International Baby Food Action Network. (2016). Marketing of breast-milk substitutes: National implementation of the International Code: Status report 2016. Retrieved from http://www. who.int/nutrition/publications/infantfeeding/code_report2016/en/

World Health Organization, United Nations Children's Fund, United Nations High Commissioner for Refugees, World Food Programme, IBFAN-GIFA, CARE USA, . . . Emergency Nutrition Network. (2007). Infant and young child feeding in emergencies (Version 2.1): Operational guidance for emergency relief staff and programme managers. Retrieved from http:// www.who.int/nutrition/publications/emergencies/operational_ guidance/en/ 